EPSC Abstracts

\title{
Elusive ice clouds in the upper mesosphere of Venus
}

Thomas Mangan ${ }^{1}$, Anni Määttänen ${ }^{2}$, Benjamin Murray ${ }^{3}$, and John Plane ${ }^{1}$

${ }^{1}$ School of Chemistry, University of Leeds, Leeds, United Kingdom (chmtpm@leeds.ac.uk)

${ }^{2}$ LATMOS/IPSL, Sorbonne Université, UVSQ Université Paris-Saclay, CNRS, Paris, France

${ }^{3}$ School of Earth and Environment, University of Leeds, Leeds, United Kingdom

\section{Introduction}

$\mathrm{H}_{2} \mathrm{O}$ ice clouds in the mesospheres of terrestrial planets have been observed for Earth as Polar Mesospheric Clouds (PMCs) and are thought to be condensed on meteoric smoke [1, 2]. In contrast, on Mars both $\mathrm{H}_{2} \mathrm{O}$ and $\mathrm{CO}_{2}$ ice clouds have been observed [3, 4]. These clouds play an important role in redistributing condensable material and the chemistry of the mesospheres of Mars and Earth. The possibility of sub-visible $\mathrm{H}_{2} \mathrm{O}$ ice clouds on Venus was speculated in 1983 by Turco, et al. [5] based on a limited set of observations (four Pioneer entry probes), however, no high-altitude ice clouds have ever been observed on Venus. More recent satellite observations have shed new light on the extreme low temperature conditions of the upper atmosphere [6]. Through satellite observation, experimental studies and modelling, our understanding of cloud formation and composition within terrestrial mesospheric clouds on Earth and Mars has improved significantly in recent decades. Here we apply this improved understanding of mesospheric clouds and the breadth of atmospheric observations to the possibility of ice clouds on Venus and importantly whether they could be detected in satellite observations.

Figure 1 shows an example polar temperature profile for Venus and the calculated saturation ratio with respect to both $\mathrm{H}_{2} \mathrm{O}$ and $\mathrm{CO}_{2}$ ice. The temperature drops below $80 \mathrm{~K}$ between $120-130 \mathrm{~km}$, causing significant supersaturations with respect to the solid phases of $\mathrm{CO}_{2}$ and particularly $\mathrm{H}_{2} \mathrm{O}$, conditions which are conducive to ice cloud formation. 


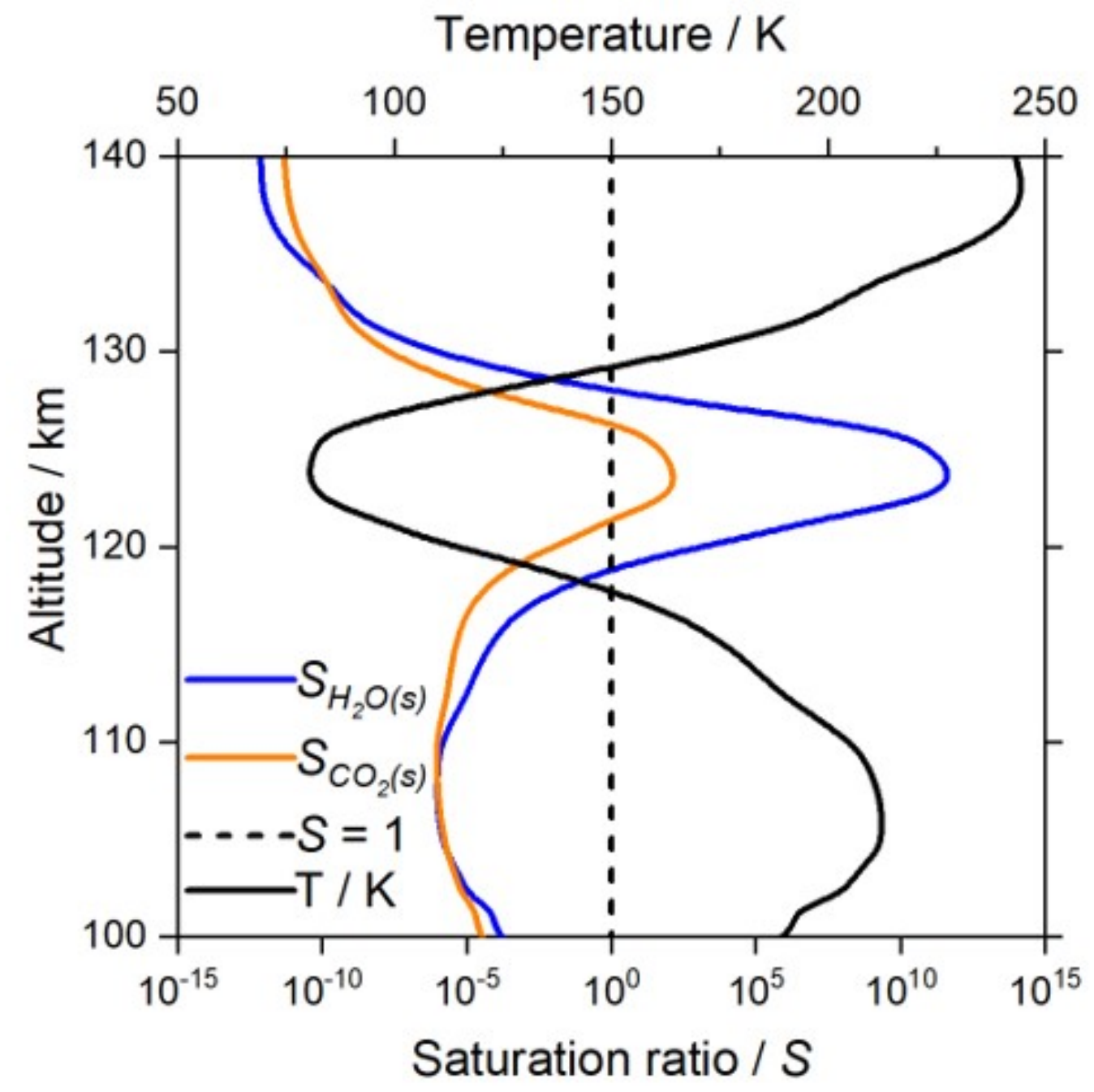

Figure 1: Saturation ratios (S) for crystalline $\mathrm{H}_{2} \mathrm{O}$ and $\mathrm{CO}_{2}$ ice derived from Venus Express observations. Here we use an average temperature profile at $70-80^{\circ}$ Lat with an assumed constant $\mathrm{H}_{2} \mathrm{O}$ volume mixing ratio of $2 \mathrm{ppm}[6,7]$.

\section{Findings}

The first step in ice cloud formation is nucleation, which we evaluate homogeneously and heterogeneously for both $\mathrm{H}_{2} \mathrm{O}$ and $\mathrm{CO}_{2}$ ice, nucleated by vapour deposition using Classical Nucleation Theory (CNT), an approach applied previously to Martian mesospheric clouds [8, 9]. Several nucleating particles are discussed and considered in the heterogeneous calculations, including meteoric smoke and in the case of $\mathrm{CO}_{2}$ nucleation, $\mathrm{H}_{2} \mathrm{O}$ ice particles $[8,10,11]$. This theory is 
applied to a planet-wide set of temperature observations (160+ occultations) from the SOIR instrument onboard Venus Express to help determine possible cloud locations and frequency. Preliminary results indicate that in the presence of suitable nanometre-sized nucleating particles, conditions exist on Venus for both $\mathrm{H}_{2} \mathrm{O}$ and $\mathrm{CO}_{2}$ to nucleate, especially where the coldest temperatures are reached in the polar regions above $120 \mathrm{~km}$. If visible clouds are possible in Venus mesosphere condensation of the primary constituent $\left(\mathrm{CO}_{2}\right.$, significantly more abundant than $\left.\mathrm{H}_{2} \mathrm{O}\right)$ onto the initial ice seeds is the likely pathway.

The growth of $\mathrm{CO}_{2}$ ice particles are then predicted under favourable nucleation conditions, using a 1D model which accounts for growth, sublimation, and sedimentation of the particles. The model shows that the clouds form in a region of the atmosphere where the pressure is very low $\left(<1 \times 10^{-2}\right.$ $\mathrm{Pa})$. The ice particles therefore sediment rapidly into a warmer layer of the atmosphere and sublimate, so that they are very short-lived (typically $<5 \mathrm{mins}$ ). Once peak particle sizes and lifetimes are determined, the extinction coefficient can be calculated for a realistic particle population using Mie theory, and hence the probability of the clouds being observed in occultation by a satellite spectrometer can be evaluated.

\section{Acknowledgements}

This work is supported by grant ST/T000279/1 from the UK Science and Technology Facilities Council.

\section{References}

[1] M. Hervig, R. E. Thompson, M. McHugh, L. L. Gordley, J. M. Russell III, and M. E. Summers, "First confirmation that water ice is the primary component of polar mesospheric clouds," Geophysical Research Letters, vol. 28, no. 6, pp. 971-974, 2001.

[2] M. E. Hervig, L. E. Deaver, C. G. Bardeen, J. M. Russell, S. M. Bailey, and L. L. Gordley, "The content and composition of meteoric smoke in mesospheric ice particles from SOFIE observations," Journal of Atmospheric and Solar-Terrestrial Physics, vol. 84-85, pp. 1-6, 2012.

[3] F. Montmessin et al., "Hyperspectral imaging of convective $\mathrm{CO}_{2}$ ice clouds in the equatorial mesosphere of Mars," Journal of Geophysical Research Planets, vol. 112, no. E11, Nov 132007.

[4] J. A. Whiteway et al., "Mars Water-Ice Clouds and Precipitation," Science, vol. 325, no. 5936, p. $68,2009$.

[5] R. P. Turco, O. B. Toon, R. C. Whitten, and R. G. Keesee, "Venus: Mesospheric hazes of ice, dust, and acid aerosols," Icarus, vol. 53, no. 1, pp. 18-25, 1983.

[6] A. Mahieux et al., "Densities and temperatures in the Venus mesosphere and lower thermosphere retrieved from SOIR on board Venus Express: Carbon dioxide measurements at the Venus terminator," Journal of Geophysical Research Planets, vol. 117, no. E7, 2012.

[7] S. Chamberlain et al., "SOIR/VEx observations of water vapor at the terminator in the Venus mesosphere," Icarus, vol. 346, p. 113819, 2020.

[8] M. Nachbar, D. Duft, T. P. Mangan, J. C. G. Martin, J. M. C. Plane, and T. Leisner, "Laboratory measurements of heterogeneous $\mathrm{CO}_{2}$ ice nucleation on nanoparticles under conditions relevant to the Martian mesosphere," Journal of Geophysical Research Planets, vol. 121, pp. 753 769, 2016.

[9] C. Listowski, A. Määttänen, F. Montmessin, A. Spiga, and F. Lefevre, "Modeling the microphysics of $\mathrm{CO}_{2}$ ice clouds within wave-induced cold pockets in the martian mesosphere," Icarus, vol. 237, pp. 239-261, 2014.

[10] D. L. Glandorf, A. Colaprete, M. A. Tolbert, and O. B. Toon, " $\mathrm{CO}_{2}$ snow on Mars and early Earth: Experimental constraints," Icarus, vol. 160, no. 1, pp. 66-72, 2002. 
[11] J. M. C. Plane, J. D. Carrillo-Sanchez, T. P. Mangan, M. M. J. Crismani, N. M. Schneider, and A. Määttänen, "Meteoric Metal Chemistry in the Martian Atmosphere," Journal of Geophysical Research Planets, vol. 123, no. 3, pp. 695-707, 2018. 